\title{
Transportation Problems in Developing Countries Pakistan: A Case-in-Point
}

\author{
Muhammad Tahir Masood, Ph.D., P.E. (Corresponding author) \\ Professor, Department of Management Sciences, COMSATS Institute of Information Technology \\ Islamabad, Pakistan \\ Tel: 11-92-342-5522-342Ｅ-mail: dr.tahirmasood@comsats.edu.pk
}

Azhar Khan, Ph.D.

Assistant Professor, Department of Management Sciences

COMSATS Institute of Information Technology, Islamabad, Pakistan

E-mail: azhar_khan@comsats.edu.pk

Hasnain A. Naqvi, Ph.D.

Assistant Professor, Department of Management Sciences

COMSATS Institute of Information Technology, Islamabad, Pakistan

E-mail: h.a.naqvi@comsats.edu.pk

Received: June 8, 2011

Accepted: July 5, 2011

Published: November 1, 2011

doi:10.5539/ijbm.v6n11p256

URL: http://dx.doi.org/10.5539/ijbm.v6n11p256

\begin{abstract}
Identifying and solving transportation problems is one of the chief tasks confronting governments in developing countries like Pakistan. Despite large expenditures on urban transport systems, the current transportation problems in developing nations continue to worsen because of bad planning, lack of governance, and corruption. Therefore, developing countries like Pakistan, have a major crisis on their hands. Urban transport problems in Pakistan are mostly managed by building larger and better roads, but building roads is not the solution. Road projects need to be part of an over-all transportation plan that includes traffic management and bigger and better transit systems and public transport. The principles of sustainable transport encourage utilization of low cost public transport capable of performing well in mixed land use and densely-populated Pakistani cities. This article highlights the core problem of continuing failure by Pakistani government to develop and manage their public transport systems to provide a high level of mobility, equity, and environmental sustainability.
\end{abstract}

Keywords: Developing countries, Transportation modes, Transportation policy, Transportation problems, Safety issues, Road rage, Traffic management, Over-population

\section{Introduction}

Exchange of goods and persons as well as the personal right of freedom both are values and benefits for themselves. Therefore, transport and mobility are constitutional elements of cities which need to be organized in a sustainable manner. Past research indicates that traffic growth will continue because of increasing mobility needs caused by economic and social activities, spatial and residential structures as well as individual behavior patterns.

Furthermore, the emergent type of urbanized or city-regions is both cause and effect of increasing mobility since regional facilities (malls, leisure parks, industrial areas or production sites) and events (sport, culture, fairs) generate regional or even inter-regional traffic. This development is ongoing and can only be structurally formed in a long-term perspective. Cities and regions otherwise suffer from this traffic pressure in form of noise, air pollution, traffic jams and accidents, but also in form of increasing infrastructure costs, less available land for other purposes and loss of "Urbanity" in terms of nearby supplies and possibilities. A permanent task for cities is to reduce the urban sprawl and the traffic impacts in order to improve the quality of life and the safety for inhabitants and road users. How to do this is an important research problem. A basic policy and research orientation could be green/zero emission and safe transport including a lot of single measures inter alia transport system dimensions (infrastructure, vehicles and operations) and land use patterns. Another important point is to raise the efficiency in terms of costs, time and natural resources as well as to improve the organizational and financial structures. Raising efficiency also includes avoiding traffic, integrating cycling and walking as an adequate means of mobility as well as reducing daily routes which could be best done with an orientation of short distances and function mingled quarters. The requirements of pedestrians as the most important road-users within the cities must set the standard for the design of streets and squares. Public transport has to be affordable 
and accessible to all population groups and especially to those who do not have any cars or individual motorized vehicles. A huge task of future mobility and transport will be the adaptation especially to elderly people's needs.

So, multi-modal transportation facilities are a basic requirement for community growth and development in a country. With the huge capital investment required to finance urban projects, the consequences of ill planning and corrupt practices have become more acute than ever. Providing successful solutions to complex mobility problems confronting urban areas require collaboration by many professionals, particularly transportation planners and traffic engineers. An inability to provide effective traffic solution management in the face of rapid population growth is resulting in undesired consequences for Pakistan and other developing countries.

Pucher et al. highlights the rapid growth of neighboring India's urban population and resulting enormous strains on all transportation systems. Burgeoning travel demands far exceed the limited supply of transportation infrastructures and services. Public transport, in particular, has been completely overwhelmed. Most bus and train services are overcrowded, undependable, slow, inconvenient, uncoordinated, and dangerous. Moreover, the public ownership and operation of most public transport services have greatly reduced productivity and inflated costs. India's cities and that of Pakistan, desperately need improved and expanded public transport service. Unfortunately, meager governmental financial assistance and lack of supportive policies, such as traffic priority for buses, place public transport in a continually deteriorating situation (Pucher) Pakistan is in a similar, or even worse, situation than India. Acute transportation sector problems are only compounded by ill-planned urbanization and enormous strains on economic development due to population explosion.

Identifying and solving transportation problems is one of the chief tasks confronting governments in developing countries like Pakistan. Despite large expenditures on urban transport systems, ranging from 15 to $25 \%$ of their total annual expenditures, the current transportation problems in developing nations continue to worsen (Khisty).

The continuing expansion of the cities like Karachi, Lahore, and Islamabad/Rawalpindi makes the daily movement of people and goods an ever-increasing complex problem. Urban growth causes multiple transportation demands on inadequate facilities. Rather than depending upon highways and major roads, cities depend largely upon their street systems for transportation services. Unfortunately, these systems are being overtaxed to meet increasing service demands for private automobile traffic, commercial traffic and public transportation. In order to address increasing urbanization and vexing problems of congestion, both short and long term strategies need to be employed. . Care and professional competence in planning and operation of highways, airports, railways, waterways, public transit, and goods terminals, is an increasing demand of society.

The purpose of this paper is not only to identify the basic traffic and transportation problems in developing countries, particularly Pakistan, but also to provide a critical overview of the causes of such problems and to suggest practical solutions based on multi-modal transport system (See Figure 1). Also, the paper identifies several factors including the importance of governance, capacity building, and urban planning in providing adequate, efficient, and effective public transport in Pakistan.

\section{Transport and Economic Development}

Everyone recognizes that, in today's world, transportation is a key element of the global economy. It has changed the face of employment, trade, family life and health care, bringing benefits that were unimaginable 100 years ago. However, the price we are paying in form of road crash mortality and morbidity for such benefits is too high. The shock and grief these events cause are all too well-known throughout the world. Their impact is particularly higher in poorer countries, where $90 \%$ of the road fatalities occur (Ahmed).

According to Nandi, an Ideal Transport System is a fully integrated safe transport network which supports social and economic regeneration and ensures good access for all which, is operated to the highest standards to protect the environment and ensure quality of life. Long run strategy should be to manage for the growth of transport demand to provide for the efficient movement of people and goods (Paavan). Transportation network of any country is of vital importance to its development and affects all sectors through economic linkages. It ensures safe and timely travel encourages business activities and cuts down transportation costs while granting produces access to markets for their goods. A reliable transportation network also provides swift access to labor force and hence generates employment opportunities. It has been widely recognized that economies with better road and communication networks are positioned more advantageously in terms of overall competitiveness as compared to economies having poor networks. Enhancements in transportation and telecommunication benefit industry, agriculture, and other services sectors as well as improving the standard of living of the general public, it is therefore, crucial that investments be made to develop and maintain an efficient network of transportation and telecommunication to ensure cost efficient integration of markets both domestically and internationally.

It is widely acknowledged that transport has a crucial role to play in economic development. More specifically, it has been recognized that the provision of a high quality transport system is a necessary precondition for the full participation of remote communities in the benefits of national development (Carapetis):

Adequate, reliable and economic transport is essential, although not in itself

sufficient, for the social and economic development of rural areas in

developing countries

The direct impact of transport on production at remote locations is derived from three effects (Carapetis, see Figure 2): 
Lowering of production costs;

Increased producer prices; and

Encouragement of investment.

Urban transport problems in Pakistan are managed by building larger and better roads. By contrast, the principles of sustainable transport encourage using low cost public transport that could perform well in mixed land use and high density Pakistani cities. The purpose of this paper is to provide a critical overview of public transport policy in Pakistan from the British India period through to recent years. This overview highlights the core problem of the continuing failure of Pakistani cities to develop and manage their public transport systems in such a way as to provide a high level of mobility, equity, and environmental sustainability. The paper identifies several factors, including the importance of governance, capacity building, and urban planning in providing adequate, efficient, and effective public transport in Pakistan.

\section{Transportation Issues}

The transport in general and the road transport in particular in Pakistan is facing critical impediment. Some of these problems are:

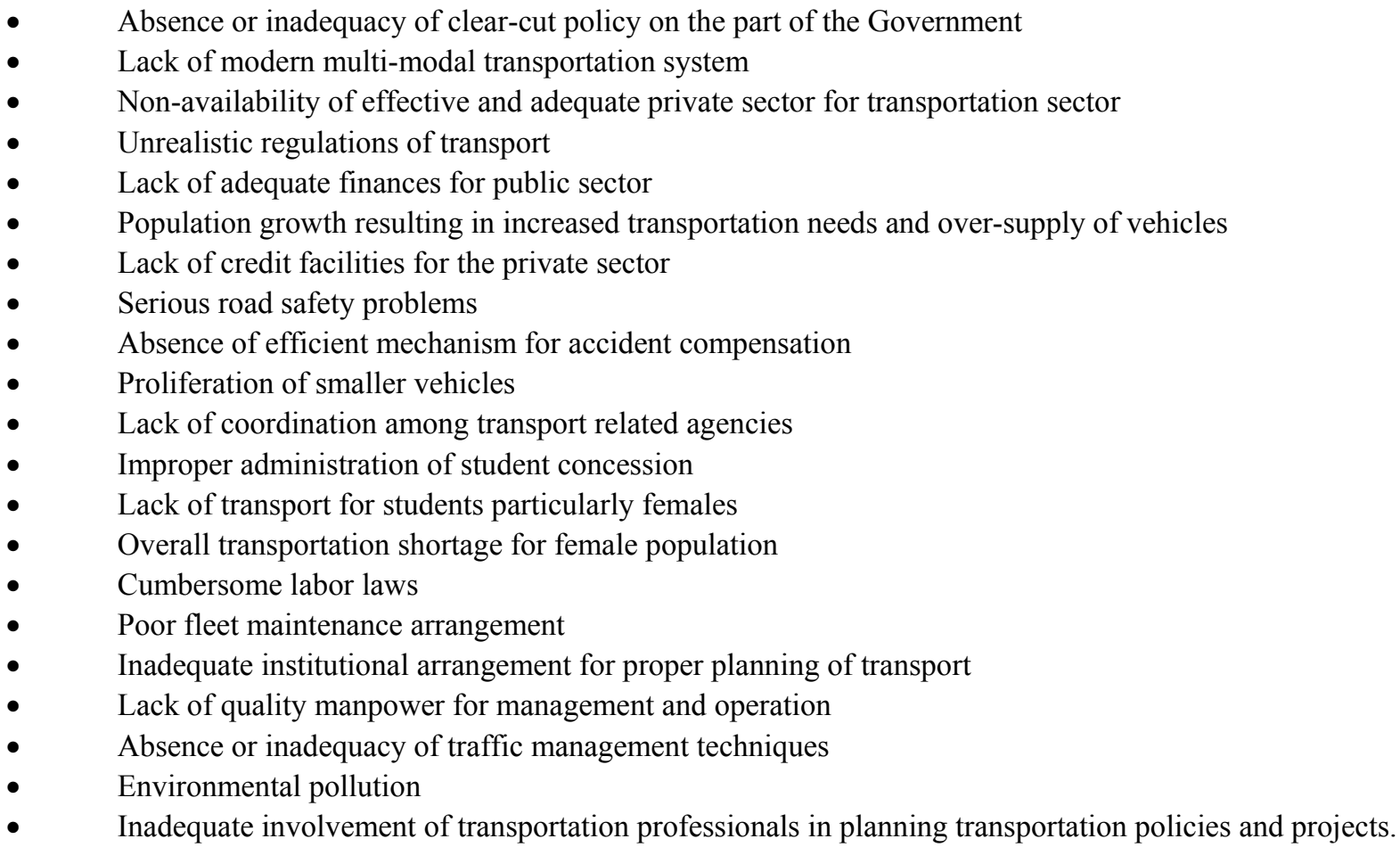

\section{Critical Issues}

Some of the critical issues impacting development of transport in Pakistan are discussed as follows:

\subsection{Policies}

This is foremost among the critical issues affecting transportation development. In Pakistan, we are continuously having a controversy amongst the professionals and policy makers over the inter-modal distribution of traffic. The role and suitability of various types of modes which form the basis for the national transport system is an important factor. Every mode has its own role. Railway is designed and suited for long hauls. In Pakistan it is understood that $80 \%$ of railway hauls is $50 \mathrm{Km}$ or less. In short hauls railway is inefficient and uneconomical. Railway system is to be planned and established on the number of long hauls both for carrying passengers and freight. As a result of political pressures railway, in the past, is forced to open new stations and maintain some uneconomical ones. Similarly some of the railway lines were laid by the British before 1947 for military during World War II or for some other purposes. Today these tracks may have to be maintained by the railway on political or social grounds even they are financially uneconomical. In developing countries, we think that transport has to be regulated and the government must always interfere but these regulations need to be constructive. In Pakistan, we cannot expect that the public sector will take care of all the transport needs of the nation. It does not happen in the developed countries and cannot be expected to work in underdeveloped and developing countries. Private sector plays very important part in hauling passengers and freight in the urban and rural areas and between the cities. In the past, $80 \%$ of the load was taken by the private sector while the public sector took $20 \%$ only. Now, public sector is hardly taking any load. Control on the fares is another problem which is adversely affecting the efficiency of the private sector. During the past few years, the cost of tires, tubes, gas and parts, etc., has increased many times whereas fare increases are only a fraction of this. To say, the fares for various urban bus transport are generally $35-60 \%$ lower than what would be a reasonable level. It has 
thus become difficult for any private entrepreneur to even recover the cost by operating within the confines of the law, i.e., no over-loading and no overcharging, etc. The outcome is inefficiency, violation of safety rules, corruption and violation of laws.

\subsection{Vehicle Mix}

In the past, the public transport like Omni-buses in cities operated with government subsidies providing it as a social service. Due to mismanagement and ill planning, the public transport like Omni-Bus in Lahore, failed in all the cities. One of the suggestions to solve the transport problems in a city is always to eliminate rickshaws and minibuses, etc. Then, there is a demand for underground rail (subways) facilities in all major cities. This is primarily due to lack of understanding of the role of various modes of urban transport. The elimination of rickshaws, Suzukis and minibuses would be very undesirable due to the fact that the transport system of any city is like a tree. It has a trunk, main branches, secondary branches, tertiary branches and leaves, all performing useful functions and required in their own right. Urban transportation system based on large buses would be like a tree without branches and leaves. Beside, using a bus, where a small Suzuki and a rickshaw can do the job, would be very wasteful. Every mode from walking and cycling to buses is part of the hierarchy of an urban transport system and must be put to its optimum use. Basic and the oldest mode of transport is our feet which we continue to use even today. Bicycle is next, then come the motorcycle followed by small vehicles like Suzukis, then are van pickups and last are the trucks, buses, trains and planes. For a balanced and economical viable transport system in developing countries, there will be a need to plan a system with a mix of vehicles. In the past, due to political pressure, a bus route was some time extended to a locality where the number of passengers might be very few. Similarly, air service is introduced by the government without proper feasibility study and because some strong politician wants it.

\subsection{Underground Rail}

In the past, there has been a lot of controversy in the press in Pakistan and other developing countries about going for the option of having underground or on-ground light rail train system. On the face of it, underground system presents a very attractive solution to the transport needs of big cities. The supporters of underground rail systems often overlook the initial capital cost of such a project. Studies have shown that the capital cost is approximately over 100 million US dollars per Km with a minimal construction length requirement of $150 \mathrm{Km}$ due to scale economics. For example, the underground rail investment for Karachi, Pakistan's largest city, would be USD 15 billion. Most of the underground systems (e.g. Paris, London) depend heavily on the government subsidies with a direct correlation between traffic volume and subsidy costs to operate them. In planning circles, there is complete unanimity that further construction of underground facilities is not economically feasible for Pakistani cities.

\subsection{Research and Development}

This is another transportation critical issue. Some people say that Pakistan is too poor to do research. It is otherwise. If Pakistan was rich like Saudi Arabia she may not bother about research and development because then she could buy the latest technology and use it. In fact the developing countries need research more than any developed or rich country so that they can devise ways and means to plan and operate their transport system efficiently and economically using their indigenous resources. Pakistan's plans are based on assumptions whereas they unlike the advanced nations, have to be based on indigenous resources.

\subsection{Management}

Today we are living in the age of specialty. A person who may not have the requisite qualifications and experience of transportation may be appointed to make policy or manage projects in this sector. This negates the basic principle of good management. It is proposed that a person in a particular system should be allowed to make it a career job. He/she must have the relevant transportation qualifications and be familiar with the principles and techniques of good management before they are asked to make the policy or manage a transportation project. Universities should run professional degree programs in management, city planning, and transportation to produce professionals to meet the demand of organizations.

\subsection{Policy of Maintenance}

Pakistan has been receiving a lot of financial assistance for various projects from International Donor Agencies like USAID, ADP and World Bank, etc. Some agencies like, USAID would interfere in our existing road construction and maintenance policy. US built a good Inter-state highway system but when it started falling apart only then they thought of the importance of maintenance of roads and bridges. Foreign concepts have been imported for Pakistan without realizing that we still need 50-75\% more roads before we start spending our resources on the maintenance of existing roads. We need to do maintenance but we need more roads as well. In the past few years, National Highway Authority has done some projects like Motorways that have somewhat helped ease the road problems; still we need more inter-city roads in Pakistan.

\subsection{Lack of Adequate Finances}

Funds to finance the transportation projects have always been short in the underdeveloped and developing countries. We need adequate funds to finance construction of new projects and maintenance of the old ones. The fund supply needs to be regular and adequate. Concept of further cooperation between the private sectors within and without the country should be looked into and applied to plan and implement transportation projects. 


\subsection{Safety Issues}

This is another critical issue of transportation. Particularly, the road safety situation has already deteriorated to extremely dangerous levels and Pakistan now ranks as one of the highest accident rate countries in the world. Airline safety-record is better. Road conditions, inadequate signage, lack of driver education and training, and law enforcement within the cities and between cities are the major causes of accidents. Corruption in traffic police is a major safety issue and we all are aware of this problem. Providing better pay and more benefits along with enforcement police cars and radar equipment may help in the police efficiency and reduce corruption. Traffic education in the schools and media campaigns could also help in improving the safety on the roads (World Bank)

\subsection{Unusual Transportation}

Due to shortage of public transport, people resort to what is called novel/unusual use of transport (See Figures 3 and 4). In fact, people are forced to violate safety laws and take risk of losing their lives or getting injured because, there is shortage of public transportation and they have no other choice (Marcofolio.net).

\subsection{Integration of Transport Modes}

The road transport, railways and even airline need to plan and operate integrated projects. Paris transport system provides a good example where you can travel on one ticket by the underground (metro), buses and railways. The present level of technological development and the State-of-the-art of transport planning make a number of remedial options available for every problem. However, the critical requirement is the precise diagnosis of the problem itself. This needs understanding of the critical issues of transport by all concerned with planning and operation of transport system.

\subsection{Lack of Planning and Corruption in Public and Private Sector}

Lack of adequate planning combined with corruption is among the factors responsible for the failure of the development of an efficient public transport system in Pakistan. The role of the private sector, lack of capacity among public transport organizations, negligence in the development of high-capacity public transport, and failure to utilize existing land use patterns for the development of reliable and efficient public transport have been identified as major factors required to develop an efficient transport system for the country. The importance of governance, capacity-building including investment, and urban planning to provide adequate, efficient, and effective public transport in Pakistan are critical for the national development.

\section{Future Plans to Resolve the Transportation and Traffic Problems}

Urban transport problems in Pakistan are managed by building larger and better roads. By contrast, the principles of sustainable transport encourage using low cost public transport that could perform well in mixed land use and high density Pakistani cities. The purpose of this paper is to provide a critical overview of public transport policy in Pakistan from the British India period through to recent years. This overview highlights the core problem of the continuing failure of Pakistani cities to develop and manage their public transport systems in such a way as to provide a high level of mobility, equity, and environmental sustainability. The paper identifies several factors, including the importance of governance, capacity building, and urban planning in providing adequate, efficient, and effective public transport in Pakistan. institutions, and provide alternative sources of financing for road safety measures (Imran).

Pakistan needs to make the future comprehensive transportation policy based on realistic short and long term plans. It is understood that during the past ten years or so a lot of work has been done in the transportation sector whereby cities like Karachi, Lahore, and Islamabad have taken various steps to improve the streets and roads and mitigate the traffic problems including police efficiency. But more needs to be done by implementing future projects under short and long term plans by using integrated mode approach and modern technology and involving private investors from within and without the country. Continue improving the existing streets and roads and adding more roads, but that is not a comprehensive and long term solution. Pakistan's population in the cities as well as in the country is growing and more vehicles are being added every day. There is a need to make long term plans to build Light Rail Vehicle (LRV) trains in our cities and use the concept of Park \& Ride as is being used in many cities in the world. Houston is the fourth largest US city which is growing fast. People in this city had been pro-roads and automobiles. Public transport use had been minimum. Texans always opposed LRV or Mono-rails but now they have finally realized the need for a train service. Seven and a half miles of LRV (Siemens built it) connecting Downtown with Texas Medical Center opened in January 2004 and it has proved a success carrying 40,000 riders a day. Now the feasibility studies on four more lines connecting Downtown with the two big airports and activity/commercial centers have been completed and they are in the planning and design phases (See Figure 5).

\subsection{LRV Train}

Here for example, two sketches (not to scale) have been prepared to propose a LRV system for Islamabad and explain the concepts. The exact LRV line alignments, number and location of LRV stations and number and location of Park \& Ride lots should be determined after a feasibility study that can be done in two parts preliminary and then comprehensive. The studies should be done by the government (self-funded or through international donors), but actual project construction and operation of the system could be done by international investors in collaboration with local financiers: 


\subsubsection{Option I}

Plan a LRV line from the new airport to Islamabad Secretariat (call it Rawalpindi - Islamabad Secretariat Corridor) and to south Rawalpindi (call it Mall Road Corridor). LRV Authority should provide free and secure Park \& Ride lot at each station where people park their cars/motorcycles and ride LRV. People without cars should use private minivans and buses running from the neighborhoods to LRV stations. This option is convenient but the traffic will be heavy due to cars and motorcycles going to the rail stations. (See Figure 6).

\subsubsection{Option II}

In the second option, proposed LRV lines are the same but the P\&Rs are proposed in the neighborhoods away from the LRV stations. No cars and motorcycles should be allowed on roads leading to the LRV stations. Only public transport (minivans, buses, and coasters) should be allowed to transport passengers from P\&R lots to the LRV stations. This option will help in reducing the traffic congestion and environmental pollution inside the two cities of Rawalpindi and Islamabad (See Figure 7).

\section{Other Technologies}

Other technology that can be studied is Monorail (See Figure 8) which has advantages and disadvantages as compared to LRV technology. The rail line alignment and concept should remain more or less the same for both the technologies. Comparison of the two technologies viz-a-viz for the twin cities is a good topic for the next article.

\section{Islamabad - Rawalpindi}

A city needs a comfortable, reliable, and safe transportation system that is environmentally acceptable. Government Bus System failed years ago. Currently, the twin cities do not have a proper bus service. Private sector operates minivans and Suzukis, etc., that cannot cope with the public demand. Huge number of motor cycles and yellow cabs have been introduced in the system but, common citizens cannot afford the taxi fares. Islamabad population which is about 1 million plus and the annual growth is six percent. Rawalpindi population is more than 2.5 million with a growth rate of about 3.5 percent. More than 150,000 vehicle ply on Islamabad roads and an average of more than 5000 to 6,000 vehicle are added every month. Supply of public transport cannot keep up with fast increasing demand. The result is traffic congestion, accidents, and environmental pollution. In the past, the local governments in the two cities had planned to provide CNG buses that would be environmentally friendly, but the programs have not been introduced so far. The following short term and long term measures are proposed for the twin-cities:

- $\quad$ CDA and Rawalpindi local government have improved the roads and should continue improving the roads in the two cities. Where possible, provide new bicycle tracks and walkways and improve the existing ones.

- $\quad$ Identify and deal with the HOT Spots in the two cities that cause traffic jams and accidents.

- Improve further the functioning of traffic police - training, better benefits, more vehicles, and better technology to do enforcement.

- Plan a multi-modal transport system.

- Implement the plan for the new international airport as soon as possible.

- Conduct a feasibility study and introduce LRV or Monorail Technologies between the two cities.

- $\quad$ This should be a 5-7 years plan. Like telecommunication sector, national and international investors should be should be encouraged to join in this project. They should be involved in planning, designing, and operating the LRV/Monorail system in the twin-cities.

- $\quad$ Expand and improve the research facilities at the Pakistan National Research Center and Military College of Engineering (Transportation Center). Establish a Multi-modal Transportation Research Center at COMSATS Institute of Technology.

\section{Conclusion}

The rapid and often unplanned and uncoordinated growth of cities has seriously compromised existing transportation systems and significantly increased the challenge of creating future transportation systems especially in developing countries. It is indeed in developing countries that the greatest growth in motor vehicles has been seen in the past few years and is expected in the future, primarily in urban areas. The environmental and social impacts are significant and directly related to quality of life and urban productivity. These impacts include congestion, energy consumption, air pollution, and traffic crashes. Thus, urban transportation issues are of foremost importance to support the mobility requirements in these growing cities and require new approaches. However, urban transport is a political rather than a technical issue. The technical aspects are relatively simple. The difficult decisions relate to the type of city we want and the way we want to live (UNITAR).

Transportation network of any country is of vital importance to its development and affects all sectors through economic linkages. It ensures safe and timely travel encourages business activities and cuts down transportation costs while granting produces access to markets for their goods. A reliable transportation network also provides swift access to labor force and hence generates employment opportunities. It has been widely recognized that economies with better road and communication networks are positioned more advantageously in terms of overall competitiveness as compared to economies having poor networks. Enhancements in transportation and 
telecommunication benefit industry, agriculture, and other services sectors as well as improving the standard of living of the general public, it is therefore, crucial that investments be made to develop and maintain an efficient network of transportation and telecommunication to ensure cost efficient integration of markets both domestically and internationally (Khan).

Today, Pakistan is surmounted by huge problems like terrorism, corruption, political instability, ill-planned urbanization, and uncontrolled population growth (3.25 crore in 1947 in the former West Pakistan rose to 18.7 crore in 2011) to name a few. These problems in turn have serious adverse impacts like danger for economic development, low per capital income, low rate of saving, problems for education sector, housing problems, food shortage and high market prices, unemployment, and transportation and environmental problems (AZY).

In this paper, we discussed the transportation sector and did a critical review to identify some of solutions to the problems. In the past few years, efforts have been made to improve transportation in Pakistan and mitigate the traffic problems in our cities, but much more is still needed to be done. The traffic problems are growing in the twin cities (Rawalpindi and Islamabad), Karachi, and other cities due to flagrant violation of traffic rules. City traffic departments and local governments have tried to improve the roads by widening them, putting signs, marking the pavements, and installing signals. But, most of the drivers do not follow the traffic rules and drive their vehicles off the lanes and ignore red light signals. The drivers using full lights, vehicles having smoking emitting engines, horn blowing, illegal parking, picking up of passengers by taxis, rickshaws and minivans in the middle of roads, aggressive driving, lack of driver education, driving without a license, and lack of proper enforcement are some of the traffic issues that need to be addressed. Karachi and Lahore have many traffic issues, but our observation is that the twin cities may be worst. It may be easier and safer to drive in Karachi than other Pakistani cities. Traffic enforcement has improved over time, but still traffic police needs better pay, better training, and more resources. Also, serious steps need to be taken to eradicate corruption in the traffic police department. Short and long term transportation plans should be based on sound government policies prepared by transportation and other professionals. Keep improving and expanding the road system by using modern technologies like High Speed Rail between cities and LRV or Monorail in the big cities of Karachi, Lahore, and Islamabad-Rawalpindi as part of the long term transportation plans. Mass transit study for Islamabad-Rawalpindi is had been planned by some foreign consultants but it was never completed to give some realistic plan. Such a study was meant to consider and evaluate all transportation modes including underground rail. They may consider the underground option to make the study look good and comprehensive, but underground rail is very expensive to build and operate. LRV should come out to be the most viable option. Government should encourage and invite the private investors (within and without the country) to invest in our long term plans to improve and operate our inter and intra cities transportation.

\section{References}

Ahmed, Aizaza. (2007). Road Safety in Pakistan. National Road Safety Secretariat, Ministry of Communications. Government of Pakistan. [Online] Available: http://www.unescap.org/ttdw/common/Meetings/TIS/EGM\%20Roadsafety\%20Country\%20Papers/Pakista n_Roadsafety.pdf (June 2, 2007)

AZY. (2010). Major Problems in Pakistan, filed under Pakistan Issues, ILM.com.pk. [Online] Available: http://www.Major Problems Of Pakistan_ILM.COM.PK.htm (December 3, 2010)

Carapetis, S., Beenhakker, H., and Howe, H. (1979). The Supply and Quality of Rural Transportation: Transportation and Economic Development. ESCAP workshop on rural roads, Dhaka. [Online] Available: http://www.unescap.org/ttdw/Publications/TFS_pubs/pub_2017/pub_2017_ch3.pdf (January 23, 1979)

Federal Highway Administration. (2011). [Online] Available: http://www.tfhrc.gov/trnsptr/feb05/images/college.jpg (The Turner-Fairbank Highway Research Center website http://www.tfhrc.gov is now http://www.fhwa.dot.gov/research/ (May 13, 2011)

Imran, Muhammad. (2009). Public Transport in Pakistan: A Critical Overview. Journal of Public Transportation, Vol. 12, No. 2, 2009. [Online] Available: http://www.nctr.usf.edu/jpt/pdf/JPT12-2Imran.pdf (January 1, 2009)

Khan, N. (2009). Current-Economic-Situation-of-Pakistan. [Online] Available: http://www.scribd.com/doc/19255599/Current-Economic-Situation-of-Pakistan (August 31, 2009)

Khisty, C J. (1993). "Transportation in Developing Countries: Obvious Problems, Possible Solutions. Transportation Research Board. [Online] Available: http://pubsindex.trb.org/view.aspx?id=382660 (October 27, 1993)

Marcofolio.net. (2007). Unusual transportation [50 Images. [Online] Available: http://www.marcofolio.net/imagedump/unusual_transportation_50_images.html (December 22. 2007)

Nandi, S. (2008). The Role of Transport in Economic Development. Indian Institute of Management Lucknow: [Online] Available: http://www.scribd.com/doc/2423416/Role-of-Transport-in-Economic-Development (April 2, 2008)

Paavan. (2006). Major Problems facing Pakistan. [Online] Available: cozay.com/PROBLEMS-FACING-PAKISTAN-TODAY.php (January 1, 2006)

Pucher, John, Korattyswaroopam, Nisha, and Ittyerah, Neenu. (2004). The Crisis of Public Transport in India: 
Overwhelming Needs but Limited Resources. India Journal of Public Transportation, Vol. 7, No. 4.

Sladek, Deborah. (2004). Metro Rail: Houston, Texas. TEXAS EXPLORER: Travel Guide to The Lone Star State, photography by George Hosek. [Online] Available: http://www.texasexplorer.com/MetroRailHouston.htm. (June 30, 2004)

Tully, Sarah. (2007). New monorail arrives at Disneyland. The Orange County Register. [Online] Available: http://www.monorails.org/tmspages/archive012508.html.

UNITAR. (2010). Sustainable Urban Mobility. [Online] Available: http://www.unitar. org/event/urbanmobility (October 4, 2010)

World Bank. (2002). Road and Highways: Road Safety [Online] Available: http://www.worldbank.org/transport/roads/safety.htm (March 1, 2002)

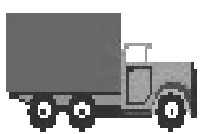

Lorry

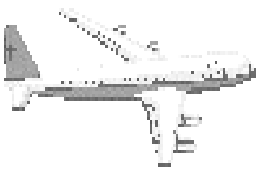

747

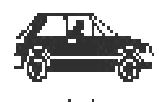

A.

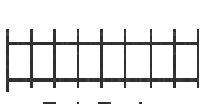

Talt That:

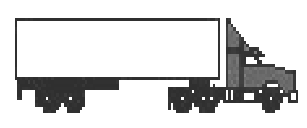

Trador Trailer
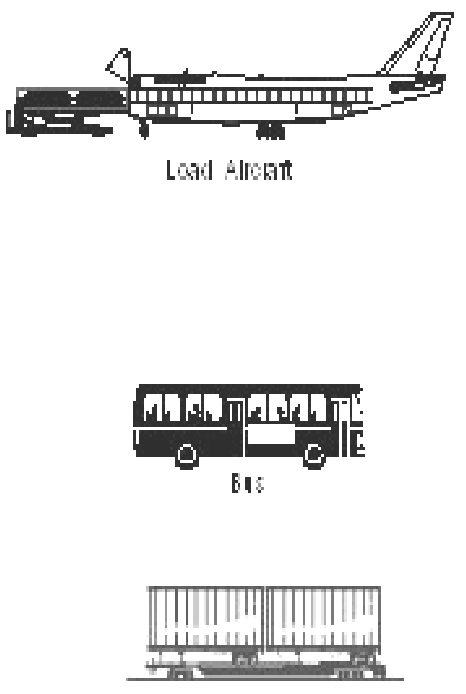

Inte modtal P. all

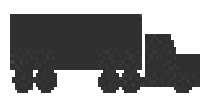

Truck
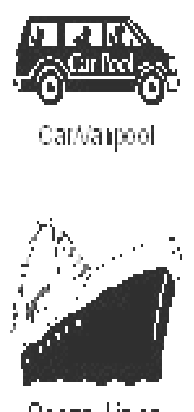

Ocean Liner
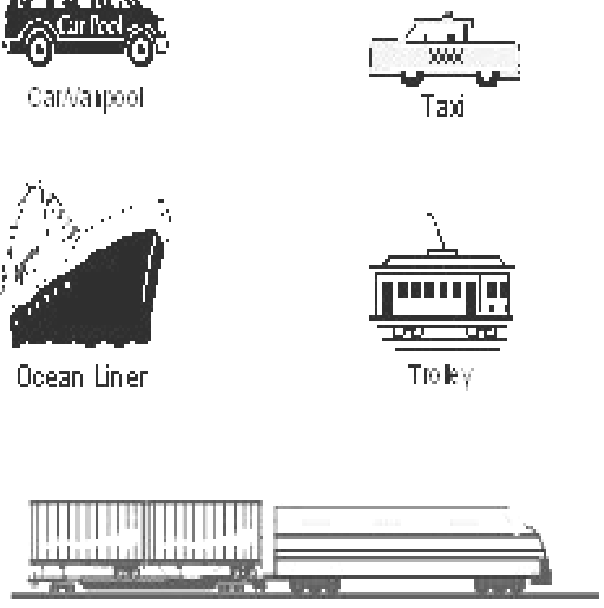

Inte minoctal P. all with Elgine

Figure 1. Transportation Modes

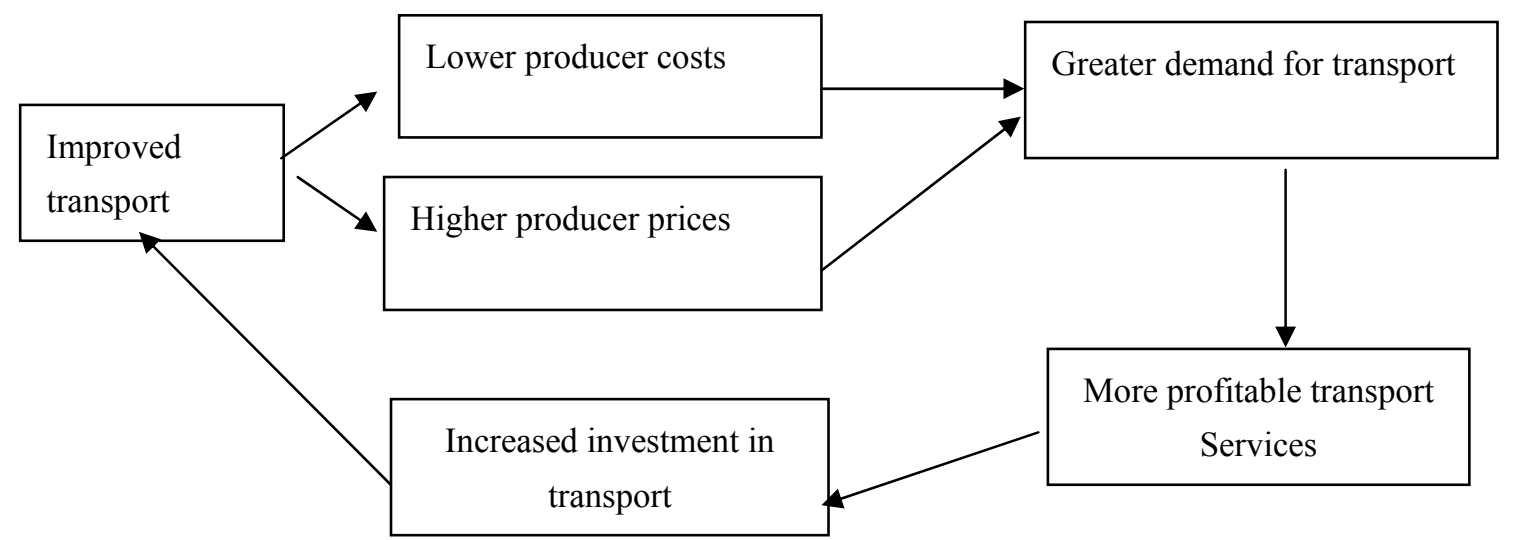

Figure 2. Relationship between Transport and Economic Development Model (Adapted: Carapetis) 


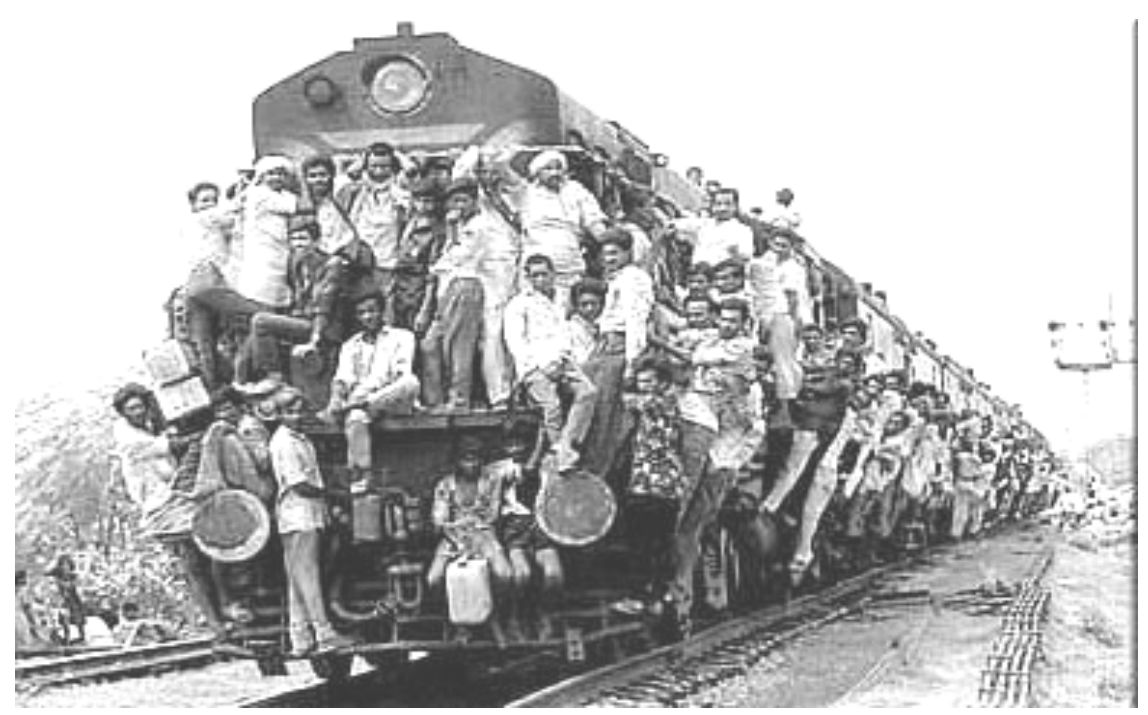

Figure 3. Unusual Transport Modes (Marcofolio.net)

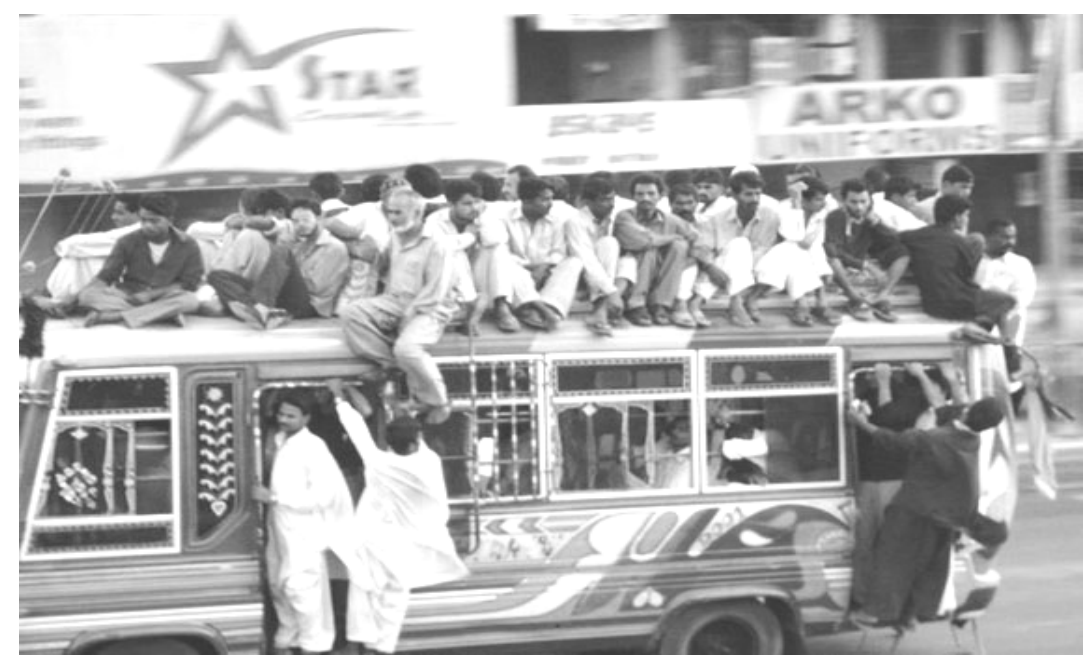

Figure 4. Unusual Transport Modes (Marcofolio.net)

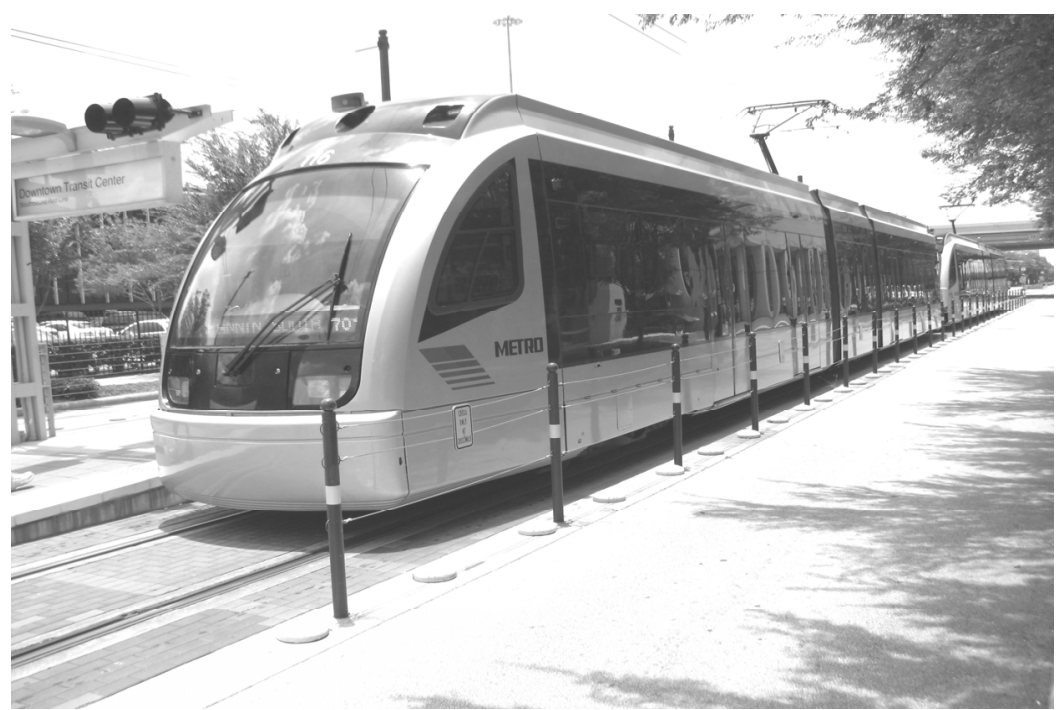

Figure 5. LRV Train opened between Downtown and Texas Medical Centre (7.5 miles) in January 2004 (Sladek) (Photo by M. Tahir Masood) 


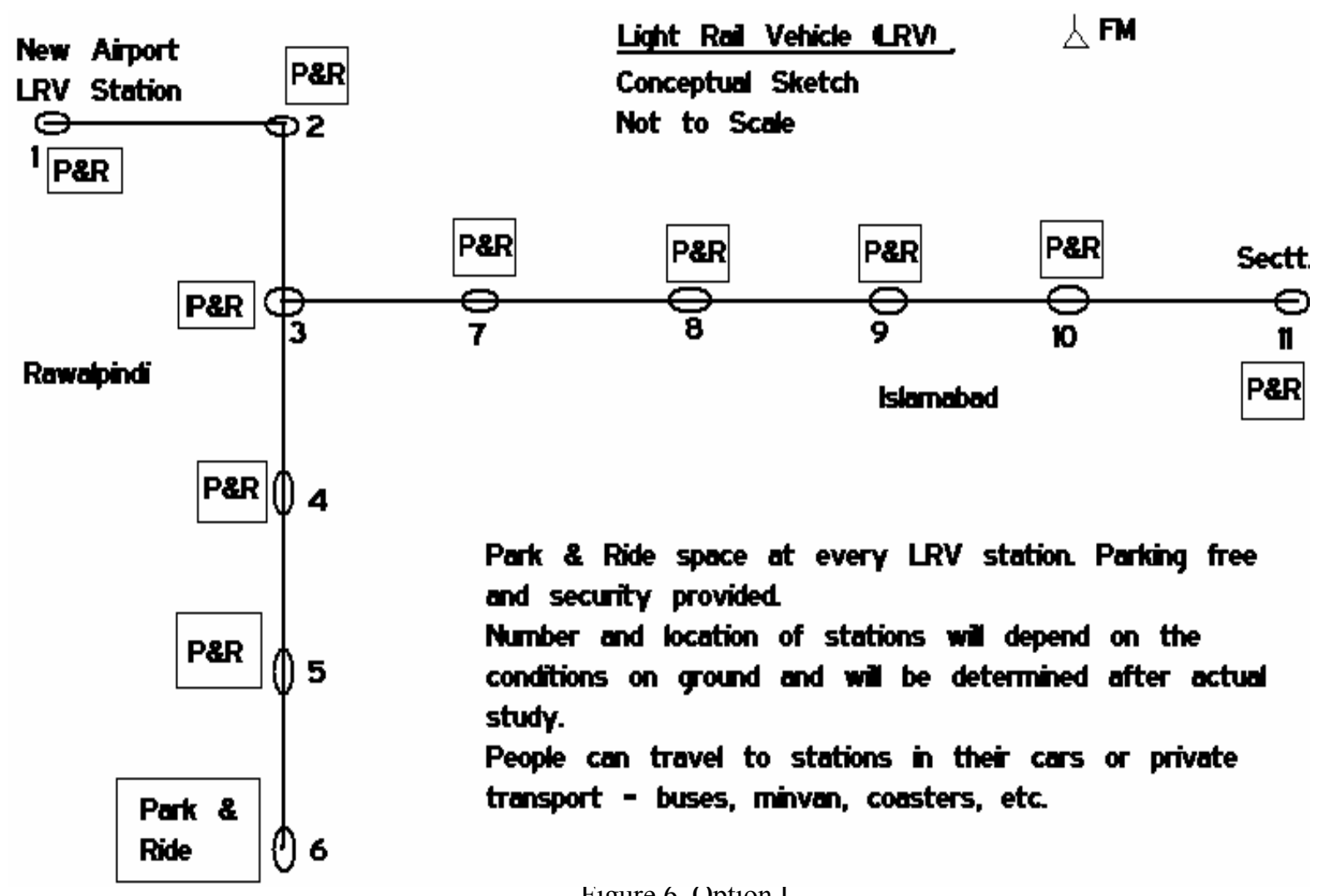

Figure 6. Option I

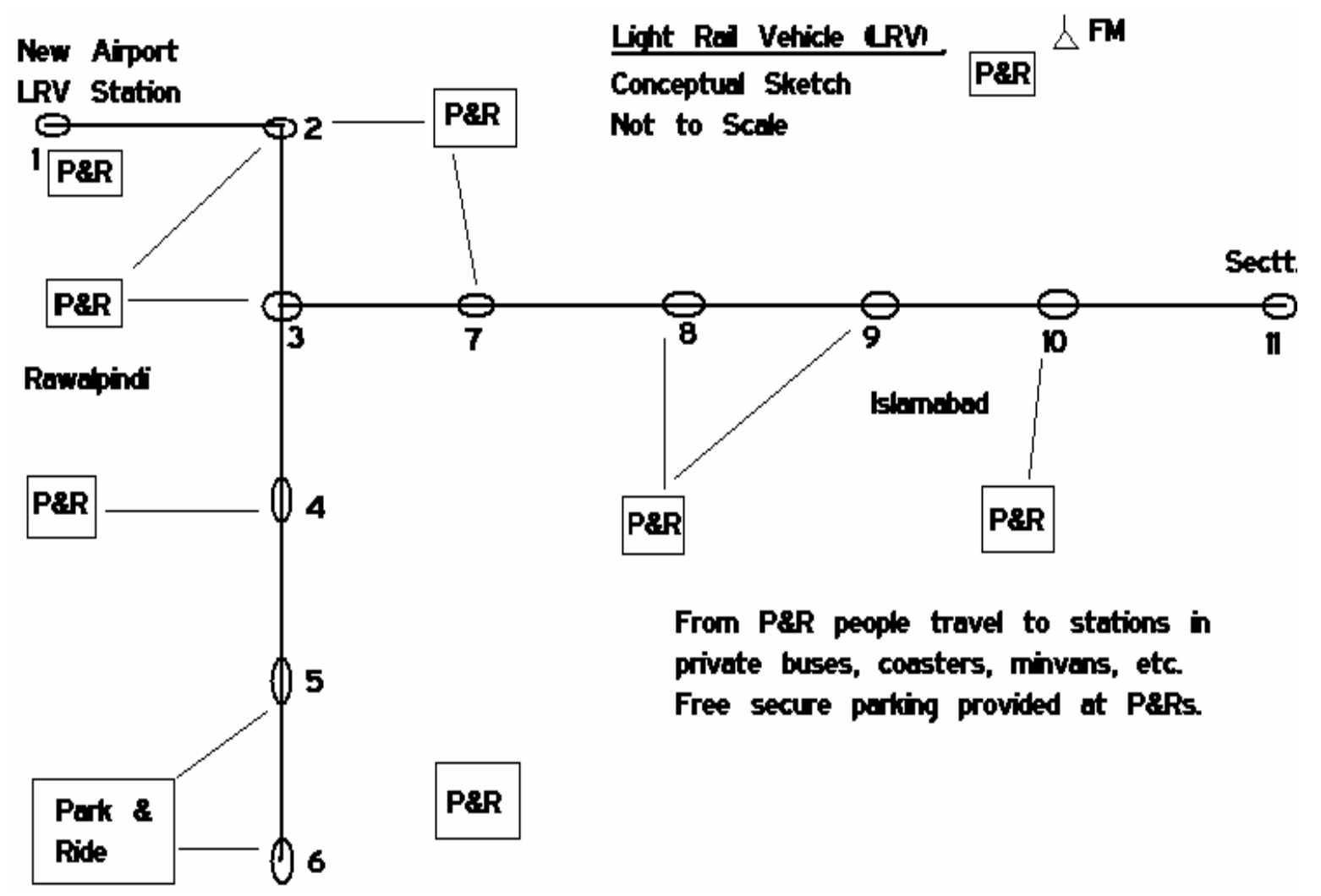

Figure 7. Option II 


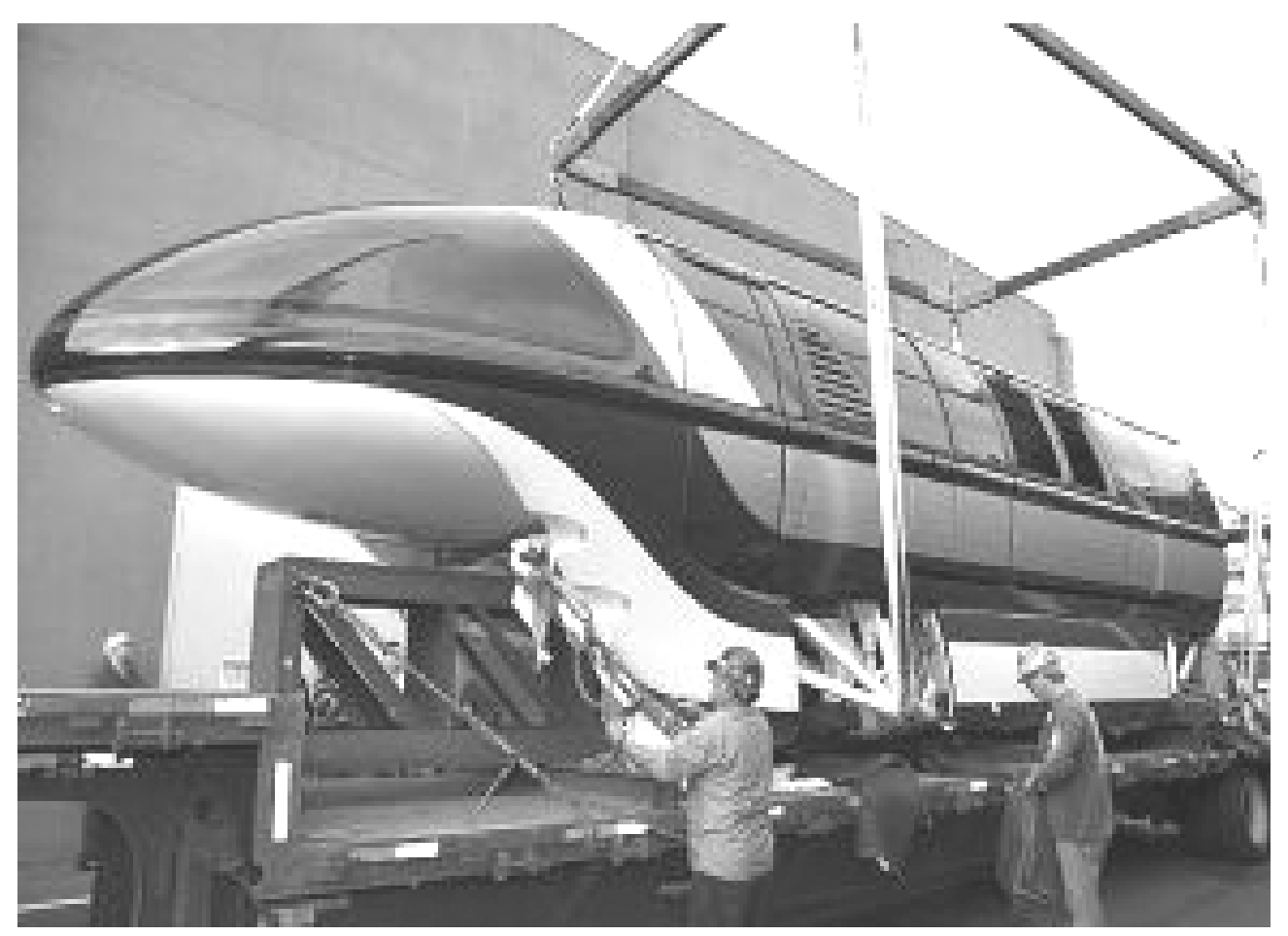

Figure 8. Monorail in Disneyland, USA

\section{Permissions for Pictures:}

Figure 1. Federal Highway Administration: http://www.fhwa.dot.gov/research

Figure 3. Marcofolio.net: http://www.linuxfocus.org/common/cc/

Figure 4. Marcofolio.net: http://www.linuxfocus.org/common/cc/

Figure 5. Sladek, Deborah: http://www.texasexplorer.com/MetroRailHouston.htm., Photograph by M. Tahir Masood

Figure 8. Tully, Sarah: htt p://www.monorails.org/tmspages/archive012508.htmly 